\title{
Comparative experimental study of dynamic compressive strength of mortar with glass and basalt fibres
}

\author{
Leopold Kruszka ${ }^{1, a}$, Wojciech Moćko $^{2}$, Luigi Fenu ${ }^{3}$, and Ezio Cadoni ${ }^{4}$ \\ ${ }^{1}$ Gen. Jaroslaw Dabrowski Military University of Technology, 2 Gen. Sylwester Kaliski St., 00-908 Warsaw, Poland \\ ${ }^{2}$ Motor Transport Institute, 80, Jagiellonska St., 03-301 Warsaw, Poland \\ ${ }^{3}$ University of Cagliari, 09123 Cagliari, Italy \\ ${ }^{4}$ University of Applied Sciences of Southern Switzerland, DynaMat Laboratory, 6952 Canobbio, Switzerland
}

\begin{abstract}
Specimen reinforced with glass and basalt fibers were prepared using Standard Portland cement (CEM I, 52.5 R as prescribed by EN 197-1) and standard sand, in accordance with EN 196-1. From this cementitious mixture, a reference cement mortar without fibers was first prepared. Compressive strength, modulus of elasticity, and mod of fracture were determined for all specimens. Static and dynamic properties were investigated using Instron testing machine and split Hopkinson pressure bar, respectively. Content of the glass fibers in the mortar does not influence the fracture stress at static loading conditions in a clearly observed way. Moreover at dynamic range 5\% content of the fiber results in a significant drop of fracture stress. Analysis of the basalt fibers influence on the fracture stress shows that optimal content of this reinforcement is equal to $3 \%$ for both static and dynamic loading conditions. Further increase of the fiber share gives the opposite effect, i.e. drop of the fracture stress.
\end{abstract}

\section{Introduction}

Concrete is considered as a brittle material. Its tensile strength is relatively low in comparison with compressive strength. In order to increase tensile properties of mortar reinforcement in a form of fibers may be included. As a consequence mortar matrix composite reinforced with fibers is created. Various fibres may be applied for the purposes of matrix strengthening, i.e. steel, glass, synthetic, basalt, carbon, organic. Diameter of reinforcement is usually within the range from $0.2 \mathrm{~mm}$ to $2 \mathrm{~mm}$, whereas length is between $25 \mathrm{~mm}$ and $60 \mathrm{~mm}$. Fibers are homogenously distributed in random directions inside the matrix, however there are some special solutions where fibers are placed along major directions.

Optimal content of reinforcement may substantially increase tensile strength of mortar composite, and slightly increase compressive behaviour. Moreover fiber presence may influence stress-strain behaviour of material. Since matrix material without reinforcement shows brittle behaviour, therefore fracture is rapid without capability to take a load after crack initiation. Addition of fiber may change this behaviour because after fracture of matrix reinforcement is responsible for carrying the load.

Basalt fibers has very good physical and mechanical properties therefore mortar based composites reinforced with this material are often used in special structures, i.e. nuclear reactors covers or high buildings elevations. Since high costs of basalt fibers application of this types of composites is limited. The second discussed material for reinforcement, i.e. glass fibre has lower tensile strength, higher elongation and three times lower

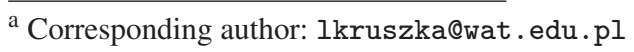

costs in comparison with basalt one. However it is not corrosive resistant what substantially reduces its practical application.

Dynamic mechanical properties of fibre reinforced composites are described by compressive dynamic increase factor (CDIF) and tensile dynamic increase factor (TDIF). In order to determine high strain rate properties split Hopkinson pressure bar (SHPB) methodology is usually applied. This technique was applied to estimate compressive and bending strength of steel fibers reinforced mortar [1]. It was found that increase of steel fibers content up to $1.5 \%$ increases both compressive (from $51 \mathrm{MPa}$ to $75 \mathrm{MPa}$ ) and bending strength (from $6 \mathrm{MPa}$ to $10 \mathrm{MPa}$ ). It was also confirmed, that fiber addition prevents brittle fracture of composite. Dynamic tests [2] done with use of pre-tension Hopkinson bar show that high performance fibre reinforced concrete properties may be strongly affected by high temperature. It is extremely important in many civil engineering and military applications where structure resistance against dynamic loadings may be lowered by fire.

This work presents analysis of compressive strength of concrete reinforced by basalt and glass fibres under quasistatic and dynamic loading conditions.

\section{Experimental method}

Both types of specimen (reinforced with glass and basalt fibers) were prepared using Standard Portland cement (CEM I, $52.5 \mathrm{R}$ as prescribed by EN 197-1) and standard sand, in accordance with EN 196-1. From this cementitious mixture, a reference cement mortar (water/cement ratio: $0,5)$ without fibers was first prepared. The fiber reinforced specimens were then prepared by adding a given fiber

This is an Open Access article distributed under the terms of the Creative Commons Attribution License 4.0, which permits unrestricted use, distribution, and reproduction in any medium, provided the original work is properly cited. 
Table 1. Flexural tensile and compressive strength of reference and fiber reinforced mortars obtained through static tests.

\begin{tabular}{|c|c|c|}
\hline Material & $\begin{array}{c}\text { Flexural tensile } \\
\text { strength } \\
{[\mathrm{MPa}]}\end{array}$ & $\begin{array}{c}\text { Compressive } \\
\text { strength } \\
{[\mathrm{MPa}]}\end{array}$ \\
\hline Reference mortar & $6,57 \pm 0,13$ & $70,20 \pm 1,65$ \\
\hline Glass fiber 3\% & $7,78 \pm 0,31$ & $57,58 \pm 2,44$ \\
\hline Glass fiber 5\% & $8,37 \pm 0,69$ & $50,46 \pm 2,13$ \\
\hline Basalt fiber 3\% & $8,72 \pm 0,97$ & $57,15 \pm 0,90$ \\
\hline Basalt fiber 5\% & $8,53 \pm 0,63$ & $52,10 \pm 1,42$ \\
\hline
\end{tabular}

content (in weight) of glass and basalt fibers to the cementitious mixture. Glass fibers and basalt fibers with same size ( $12 \mathrm{~mm}$ in length and $14 \mu \mathrm{m}$ in diameter) were used, thus allowing to better compare the respective performance in fibre reinforced concrete under dynamic loading conditions, taking into account applications of those materials to protective structures. For the same reason, both types of specimens were prepared with same fiber content (3\% and $5 \%$ in weight). Four different types of fiber reinforced mortar were hence obtained. Compressive strength, modulus of elasticity, and mod of fracture were determined for all specimens. Basic quasistatic parameters of tested materials are shown in Table 1. Static and dynamic properties of tested specimens were investigated experimentally using universal Instron 8802 testing machine equipped with Aramis measure system, and split Hopkinson pressure bar equipped in Phanton v1210 high speed camera, respectively. Quasi-static tests were carried out at strain rate equal to $0.0051 / \mathrm{s}$ whereas dynamic tests were performed at strain rate equal to $800 / \mathrm{s}$.

Split Hopkinson Pressure Bar [3-9], presented in Fig. 1, was equipped with incident and transmitter bars $20 \mathrm{~mm}$ in diameter and $2000 \mathrm{~mm}$ in length, which were made of high strength maraging steel, $\sigma_{y}=2100 \mathrm{MPa}$. The signals acquired from the strain gauges were amplified by the wideband bridge Vishay amplifier and digitized by an oscilloscope. The initial velocity of the striker, which was accelerated in a pressure gas launcher was measured by two sets of diodes and photo detectors coupled to a digital counter. Based on the waveforms recorded by a digital oscilloscope for transmitted $\varepsilon_{T}(\mathrm{t})$ and reflected $\varepsilon_{R}$ (t) waves and the known cross sectional area of the bars $\mathrm{A}$ and the specimen $\mathrm{A}_{S}$, the speed of the elastic wave propagation in the material of the bars $\mathrm{C}_{0}$ and the testpiece length $\mathrm{L}$, it is possible to determine stress $\sigma(\mathrm{t})$, strain $\varepsilon(\mathrm{t})$ and strain rate $\dot{\varepsilon}(t)$ in the specimen using the following formulas:

$$
\begin{gathered}
\delta(t)=E\left(\frac{A}{A_{S}}\right) \varepsilon_{T}(t) \\
\varepsilon(t)=-\frac{2 C_{0}}{L} \int \varepsilon_{R}(t) d t \\
\dot{\varepsilon}(t)=\frac{d \varepsilon(t)}{d t}=\frac{-2 C}{L} \varepsilon_{R}(t) .
\end{gathered}
$$

\section{Results}

The course of compression tests at quasi-static and dynamic loading conditions are shown if Figs. 2-6.

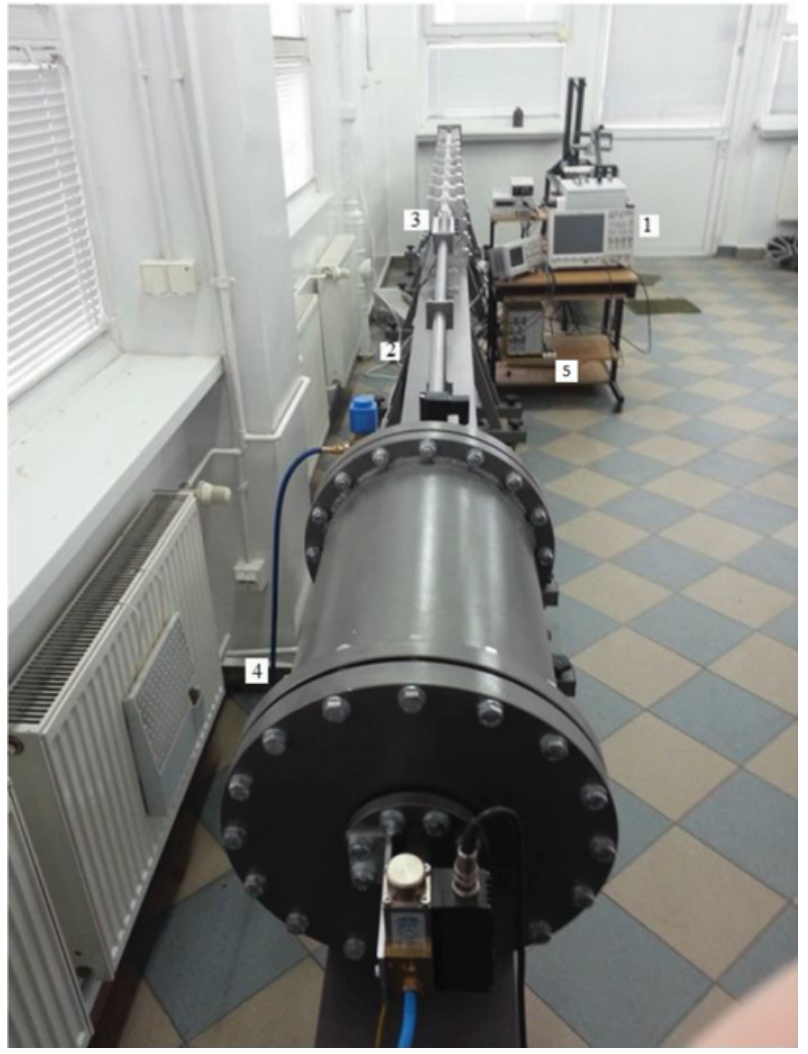

Figure 1. Split Hopkinson bar arrangement applied in the dynamic tests. 1 - digital oscilloscope, 2 - base, 3 - steel bars, 4 - pressure tank, 5 - tensometer bridge.

a)

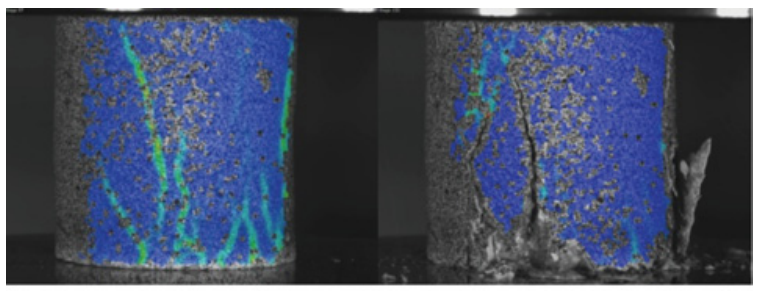

b)

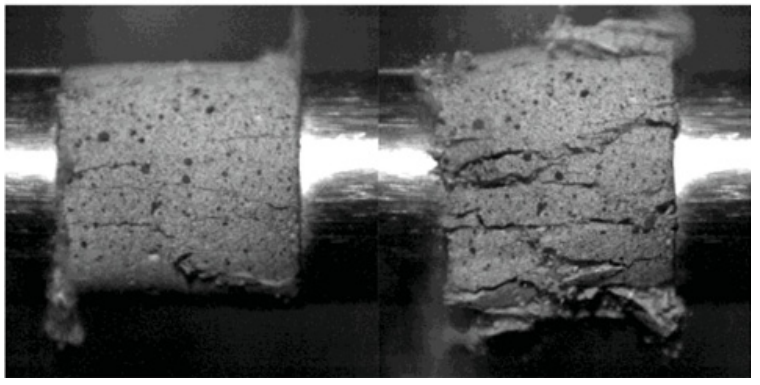

Figure 2. Deformation of reference mortar at (a) quasi-static loading conditions, (b) dynamic loading conditions.

Additionally quasi-static results were analysed using digital image correlation method. It may be observed that damage mode changes with strain rate, i.e. at quasi-static loadings number of leading cracks is lower than at dynamic loading conditions. This behaviour is independent on tested material.

Influence of reinforcement content on the compressive strength is shown in Fig. 7 and Fig. 8. Compressive strength of matrix determined at quasi-static conditions 
a)

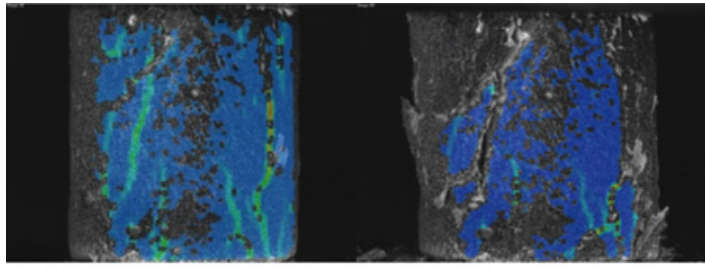

b)

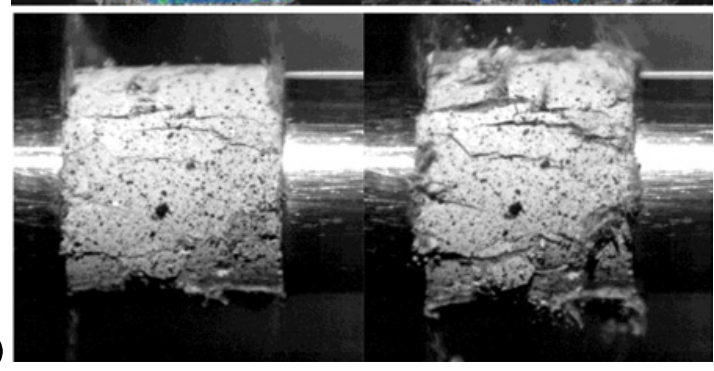

Figure 3. Deformation of specimen reinforced with 3\% of glass fiber at (a) quasi-static loading conditions, (b) dynamic loading conditions.

a)

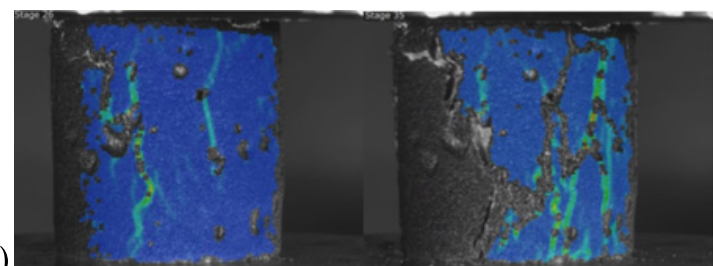

b)

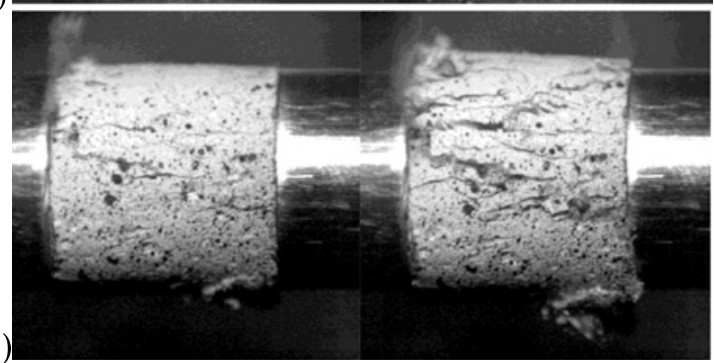

Figure 4. Deformation of specimen reinforced with $5 \%$ of glass fiber at (a) quasi-static loading conditions, (b) dynamic loading conditions.

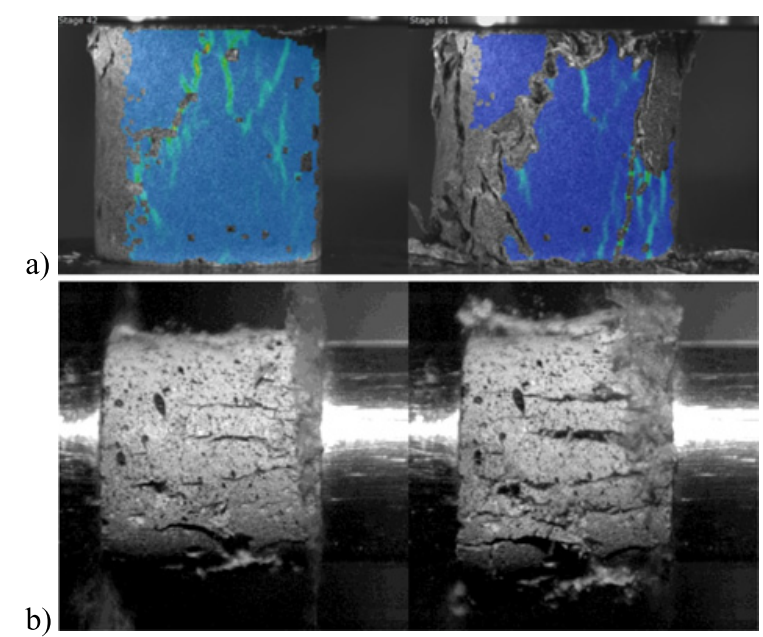

Figure 5. Deformation of specimen reinforced with 3\% of basalt fiber at (a) quasi-static loading conditions, (b) dynamic loading conditions. a)

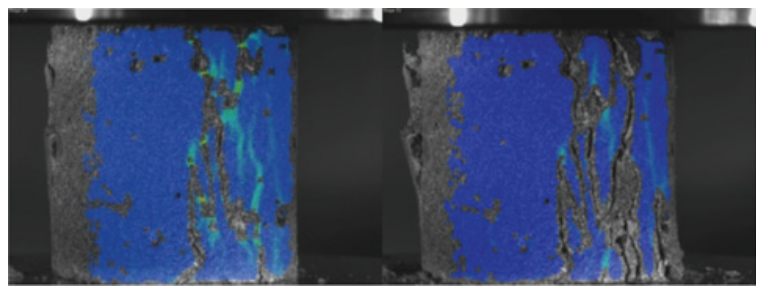

Figure 6. Deformation of specimen reinforced with $5 \%$ of basalt fiber at (a) quasi-static loading conditions.
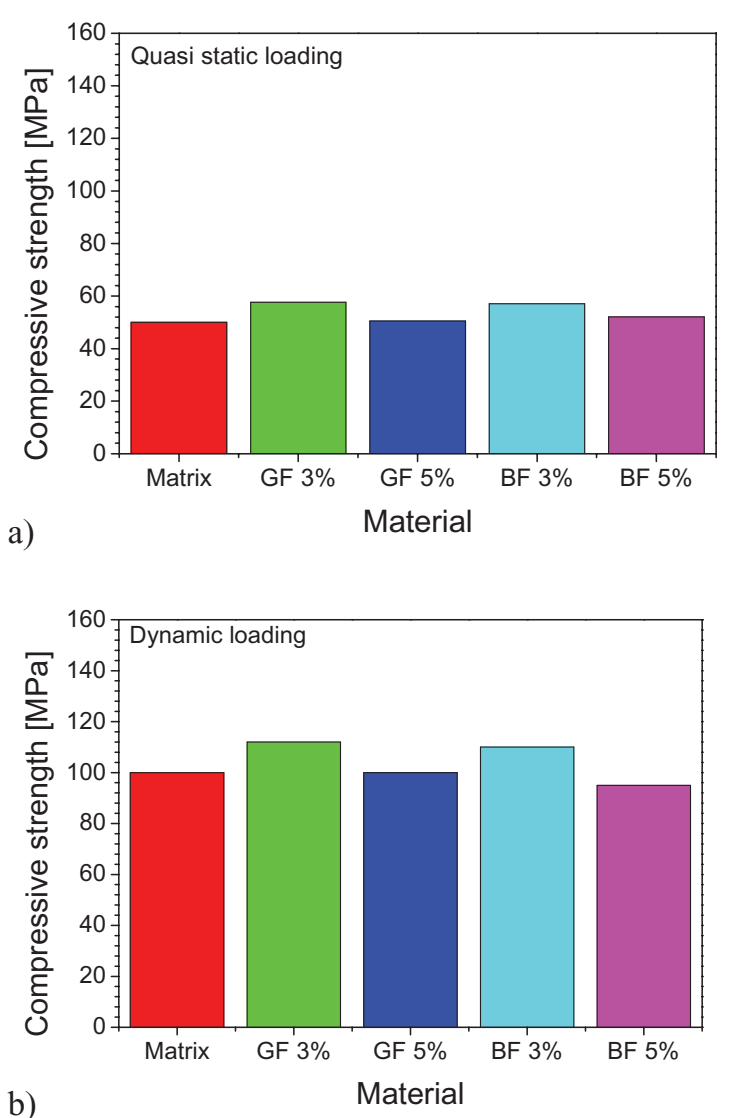

Figure 7. Compressive strength of tested materials at (a) quasistatic loading conditions, (b) dynamic loading conditions.

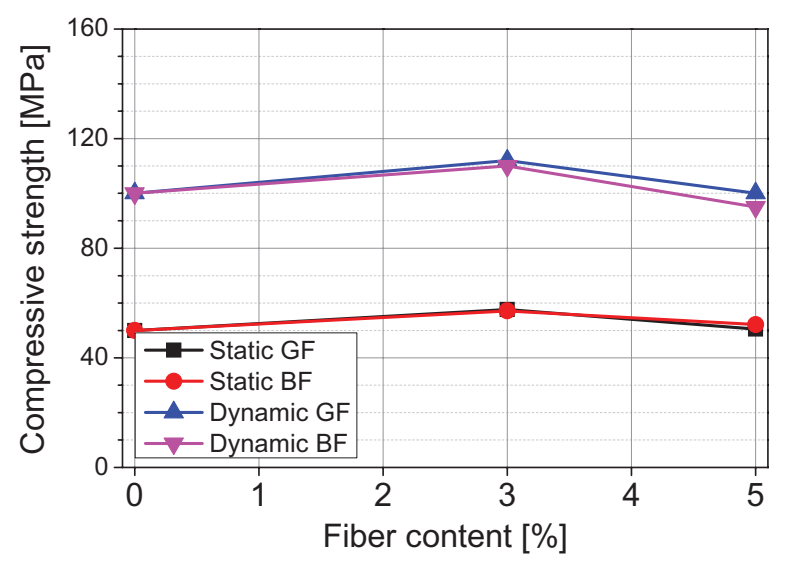

Figure 8. Influence of fiber content on the compressive strength of tested materials. 


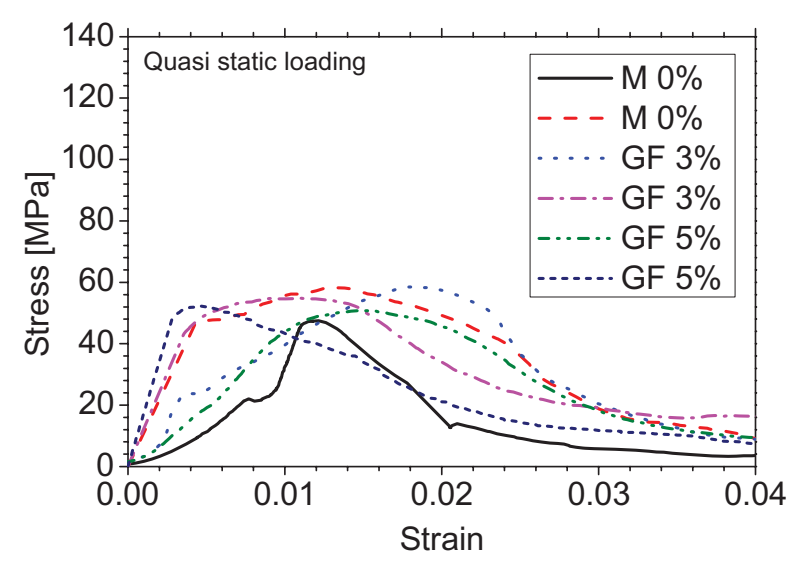

Figure 9. Stress-strain curves of reference and glass fibre reinforced mortar at quasi-static loading conditions.

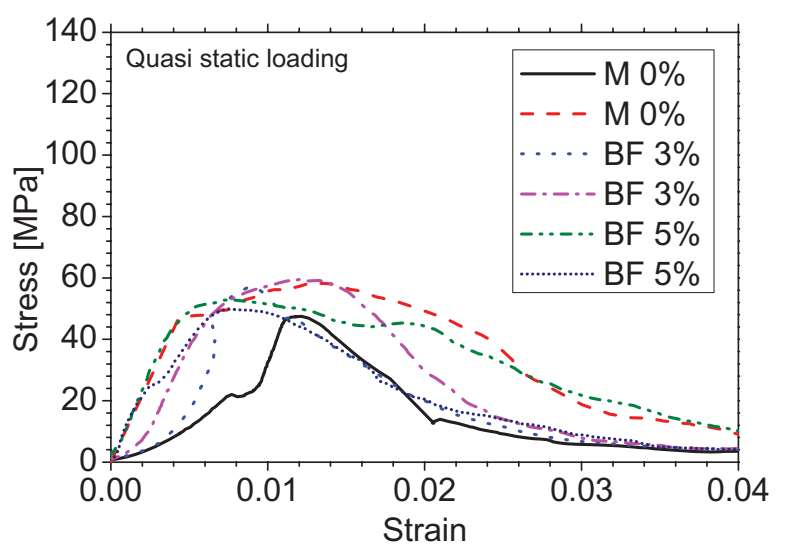

Figure 10. Stress-strain curves of reference and basalt fibre reinforced mortar at quasi-static loading conditions.

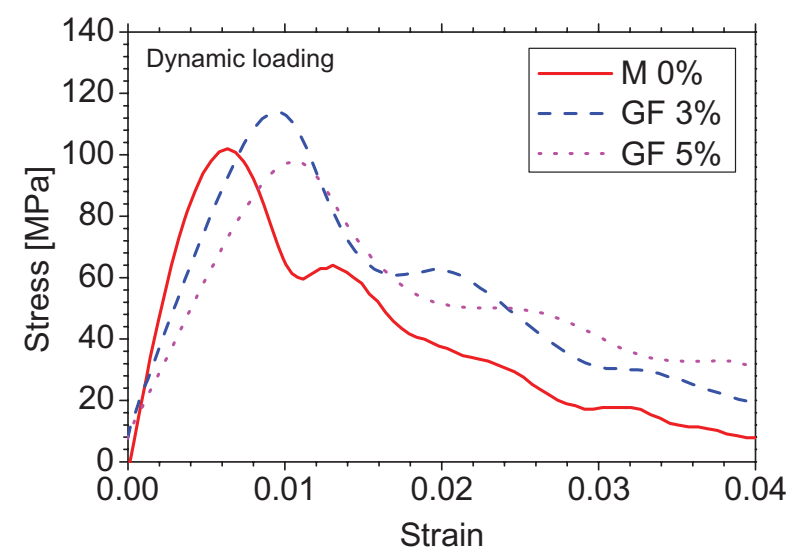

Figure 11. Stress-strain curves of reference and glass fibre reinforced mortar at dynamic loading conditions.

is equal to $50 \mathrm{MPa}$. Increase of strain rate up to $800 / \mathrm{s}$ induces increase of strength up to $100 \mathrm{MPa}$. Therefore dynamic strength is two time higher than quasi-static one. Fiber content equal to $3 \%$ gives strengthening effect at low at high strain rate deformation independently on fiber material. Further increase of fibre content results in opposite effect, i.e. drop of compressive strength.

Stress-strain curves of matrix and composites are presented in Figs. 9-12. It may be observed that in

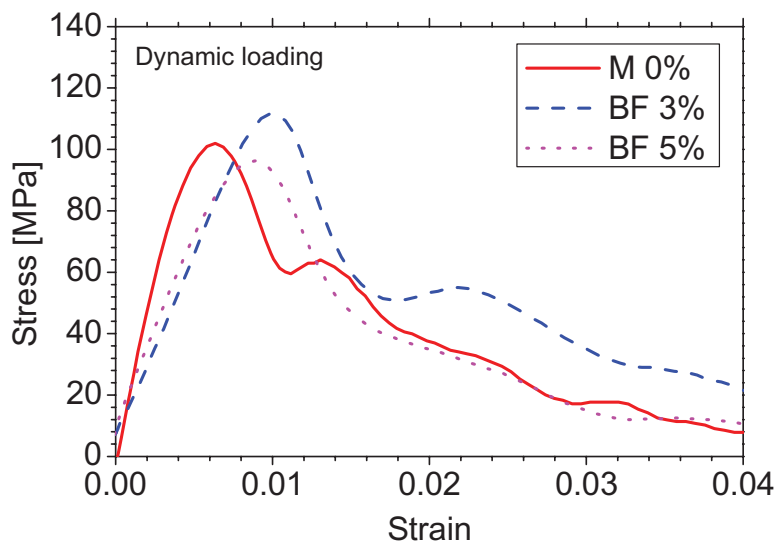

Figure 12. Stress-strain curves of reference and basalt fibre reinforced mortar at dynamic loading conditions.

the dynamic loading condition damage has more rapid character than at quasi-static one. As a consequence stress value after reaching maximum value quickly drops to 0 . Effect of load carrying by reinforcement fibers after crack initiation was not observed.

\section{Summary}

Analysis of the basalt and glass fibers influence on the fracture stress shows that optimal content of this reinforcement is equal to $3 \%$ for both static and dynamic loading conditions. Further increase of the fiber share gives the opposite effect, i.e. drop of the fracture stress.

\section{References}

[1] T. Ch. Yet, R. Hamid, M. Kasamuri, Dynamic StressStrain Behaviour of Steel Fiber Reinforced HighPerformance Concrete with Fly Ash, Advances in Civil Engineering 2012, 1-6 (2012)

[2] A. Caverzan, E. Cadoni, M. Prisco, Behaviour of advanced cementitious composites under dynamic loading and fire, In: Proceedings of the International Workshop on Structures Response to Impact and Blast. Haifa. 2009.

[3] H. Kolsky, An Investigation of the mechanical properties of materials at very hign rates of deformation of loading. Proc. Phys. Soc. 62B, 647700 (1949)

[4] W. Moćko, J. Janiszewski, M. Gra̧zka, Application of an extended Rusinek-Klepaczko constitutive model to predict the mechanical behavior of 6082-T6 aluminum under Taylor impact test conditions. J. Strain Analysis 48, 364-375 (2013)

[5] W. Moćko, J. Janiszewski, J. Radziejewska, M. Gra̧zka, Analysis of deformation history and damage initiation for 6082-T6 aluminium alloy loaded at classic and symmetric Taylor impact test conditions. Int. J. Impact Eng. 75, 203-213 (2015)

[6] W. Moćko, Analysis of the impact of the frequency range of the tensometer bridge and projectile geometry 
on the results of the measurement by the split Hopkinson pressure bar method. Metrol. Meas. Syst. 20, 555-564 (2013)

[7] W. Moćko, J.A. Rodríguez-Martínez, Z.L. Kowalewski, A. Rusinek, Compressive viscoplastic response of 6082-T6 and 7075-T6 aluminium alloys under wide range of strain rate at room temperature:
Experiments and modelling. Strain 48, 498-509 (2012)

[8] W. Sumelka, Thermoelasticity in the Framework of the Fractional Continuum Mechanics, J. Therm. Stresses 37, 678-706 (2014)

[9] W. Sumelka, Fractional viscoplasticity, Mech. Res. Commun. 56, 31-36 (2014) 